\title{
Review
}

\section{Emerging Pharmacologic Therapies for Heart Failure With Reduced Ejection Fraction}

\author{
Ammar G. Chaudhary, MBChB, FRCPC, Fadi M. Alreefi, MD, and \\ Mohammad A. Aziz, MBBS, FACC \\ Cardiovascular Diseases Department, King Faisal Specialist Hospital and Research Centre (Gen. Org.), Jeddah, Saudi Arabia
}

\begin{abstract}
The global burden of heart failure has reached epidemic proportions with tremendous health and economic consequences. Sodium glucose cotransporter 2 inhibitors, vericiguat, and omecamtiv mecarbil are novel agents that promise to blunt the high residual risk of heart failure with reduced ejection fraction. We review the vast knowledge base that has rapidly materialized for these agents and is poised to shape the current and future trends and recommendations in heart failure pharmacotherapy.
\end{abstract}

The global burden of heart failure (HF) is at least 29 million, approaching 64 million by one estimate. ${ }^{1,2}$ Developed and several developing countries are saddled with a high prevalence of cardiac risk factors and coronary artery disease, which presage the onset of HF. ${ }^{3,4}$ Although exact regional estimates of $\mathrm{HF}$ are lacking, clustering of risk factors and coronary artery disease in several developing countries suggests that regional epidemiologic trends for $\mathrm{HF}$ are at least similar if not worse than those in the United States, where $2 \%$ of the entire population is estimated to have $\mathrm{HF}^{5}$

At least half of all $\mathrm{HF}$ is attributed to reduced ejection fraction (EF), and although HF with reduced EF (HFrEF) has greatly benefited from therapeutic progress and consequently marked reductions in risk of death and hospitalization, HFrEF patients continue to suffer a high residual risk that exacts a substantial health and economic burden. 6,7 This has spurred an ongoing interest in developing new therapies by expanding the treatment landscape beyond the current gold standard of neurohormonal antagonism. We review the emerging pharmacotherapies in greater detail,

Received for publication December 10, 2020. Accepted January 17, 2021.

Ethics Statement: The research reported has adhered to the relevant ethical guidelines.

Corresponding author: Dr Ammar G. Chaudhary, King Faisal Specialist Hospital and Research Centre (Gen Org), Jeddah, Saudi Arabia. Tel.: +966 $126677777 \times 41406$.

E-mail: AChaudhary@kfshrc.edu.sa

See page 655 for disclosure information.

\begin{abstract}
RÉSUMÉ
Le fardeau planétaire que représente l'insuffisance cardiaque (IC) a atteint des proportions épidémiques en plus d'avoir d'énormes répercussions sur la santé et l'économie. Le vericiguat et l'omécamtiv mécarbil sont des inhibiteurs du cotransporteur sodium-glucose de type 2 (SGLT2) novateurs et prometteurs qui donnent de l'espoir dans la réduction du risque résiduel élevé d'insuffisance cardiaque avec fraction d'éjection réduite. Nous examinons à l'heure actuelle la vaste base de connaissances qui s'est rapidement constituée pour ces agents et qui s'apprête à façonner les tendances et recommandations actuelles et futures relatives à la pharmacothérapie de I'IC.
\end{abstract}

including their mechanism of action, evidence base, and their potential placement in the treatment algorithm for HFrEF.

\section{Residual Risk in Patients With HFrEF and New Options on the Horizon}

Recently concluded randomized clinical trials offer valuable insight into the residual risk incurred by HF patients in the contemporary era. In the Prospective Comparison of ARNi With ACEi to Determine Impact on Global Mortality and Morbidity in Heart Failure (PARADIGM-HF) trial, the investigational arm of sacubitril/valsartan was superior to enalapril, with a cumulative incidence for a composite of cardiovascular $(\mathrm{CV})$ death or first HF hospitalization of $21.8 \%$ after a median of 27 months. ${ }^{8}$ This figure, however, is remarkably high when the stable nature of patients included in this trial are considered, most (76\%) of whom had mild symptoms, adequate blood pressure (BP) to tolerate the run-in phase of both therapies, and despite exclusion of those with a current $\mathrm{HF}$ decompensation or advanced renal failure.

In the recently concluded Vericiguat Global Study in Subjects With Heart Failure With Reduced Ejection Fraction (VICTORIA), investigators sought to compare vericiguat with placebo in an elevated risk group of HFrEF patients with a history of $\mathrm{HF}$ hospitalization $<6$ months or intravenous diuretic use and $\mathrm{N}$-terminal pro-B-type natriuretic peptide (NT-proBNP) of at least $\geq 1000 \mathrm{pg} / \mathrm{mL}$. The placebo arm had a cumulative incidence of $\mathrm{CV}$ death or first $\mathrm{HF}$ 
hospitalization of $38.5 \%$ after a median follow-up of 10.8 months, a risk that was higher than expected by the investigators.?

These high event rates were observed despite study designs that ensured a high utilization of neurohormonal blocking agents, in excess of $90 \%$ for the combination of angiotensin converting enzyme inhibitors (ACEIs) or angiotensin receptor blockers (ARBs) with $\beta$-blockers. Although these and other data show a need for innovative new approaches, that need has to be balanced against the cost of development, deployment, and the unintended consequences of polypharmacy that could complicate uptake of new agents. Another challenge experts wrestle with is how to best integrate any new treatment into the increasingly complex framework of HFrEF management.

After a relative period of stagnation since the year 2000, the CV community has been fortunate to witness the emergence of several new options for HFrEF, led by angiotensin receptor-neprilysin inhibition, and followed more recently by sodium glucose cotransporter 2 (SGLT2) inhibitors, a soluble guanylate cyclase stimulator, a cardiac myosin activator, and several invasive interventions such as catheter-based mitral valve repair and cardiac contractility modulation. ${ }^{9-15}$ Several of these options are unique because they work through novel mechanisms that are independent of neurohormonal antagonism. These treatments are at various stages of scientific scrutiny and regulatory approval, and although several are approved by the US Food and Drug Administration (FDA), only 1 guideline update thus far has provided recent recommendations, with no other guideline-level recommendations yet in established HF across the United States or Europe. ${ }^{16-19}$

\section{SGLT2 Inhibition}

\section{Mechanism of action}

The SGLT2 is expressed exclusively in the initial segment of the proximal tubule of the kidney, and it is responsible for reabsorbing $90 \%$ of filtered glucose. The remaining is reabsorbed by sodium glucose cotransporter 1 (SGLT1). ${ }^{20}$ The SGLT2 is indirectly linked to the sodium potassium adenosine triphosphatase, which through an energy dependent mechanism generates a sodium gradient that drives sodium and glucose from the tubular lumen to inside the cell across the SGLT2. ${ }^{21}$ To date, 10 molecules can block the SGLT2 with varying degrees of selectivity, and most of the ones available for clinical use preferentially inhibit SGLT2 over SGLT1, because SGLT1 is also expressed in the gastrointestinal tract and its inhibition causes diarrhea. ${ }^{22,23}$ SGLT2 blockade results in sodium and glucose loss in the urine, accounting for the antiglycemic and natriuretic effects of these agents, which along with glucosuria promotes diuresis. These medications were not developed as diuretics but rather as diabetes medications, and since 2008, the FDA had advised that all new glucose-lowering agents be evaluated for CV safety. ${ }^{24}$

\section{Evidence in preventing $\mathrm{HF}$}

Four of these medications were the subject of large CV safety trials; empagliflozin in the Empagliflozin Cardiovascular Outcome Event Trial in Type 2 Diabetes Mellitus
Patients - Removing Excess Glucose (EMPA-REG OUTCOME), canagliflozin in the Canagliflozin Cardiovascular Assessment Study (CANVAS) Program, dapagliflozin in Dapagliflozin Effect on Cardiovascular Events-Thrombolysis in Myocardial Infarction (DECLARE-TIMI 58) study, and ertugliflozin in the Evaluation or Ertugliflozin Efficacy and Safety Cardiovascular Outcomes Trial (VERTIS CV). ${ }^{25-28}$ All of these trials served a similar purpose and therefore had similar overall design elements and largely produced similar results (Table 1$)$. The target population $(\mathrm{n}=42,568)$ was diabetic with a high risk of $\mathrm{CV}$ events, and that was achieved through enrichment with patients with established ischemic CV disease in EMPA-REG OUTCOME and VERTIS CV, or additionally by including those with multiple risk factors in the CANVAS Program and DECLARE-TIMI 58.

In EMPA-REG OUTCOME, empagliflozin reduced the composite of CV death, nonfatal myocardial infarction, or nonfatal stroke (hazard ratio [HR], 0.86; $95 \%$ confidence interval [CI], 0.74-0.99; $P=0.04$ for superiority), a reduction that was not attributable to a decrease in ischemic events. However, the reduction in CV death (HR, 0.62; 95\% CI, $0.49-0.77 ; P<0.001)$ correlated with a decrease in HF hospitalizations (HR, 0.65; 95\% CI, 0.50-0.85; $P=0.002$ ). Only $10 \%$ of patients had a history of HF, and the single-digit event rate was expected of a prevention trial and indicated that the benefit was because of a delay in the onset of de novo HF (Fig. 1). Canagliflozin and dapagliflozin produced similar point estimates in their respective end points for major adverse cardiac events, and despite a variance in the statistical significance of those findings, a consistent and statistically significant reduction in risk of HF hospitalization was evident across the 3 trials. Ertugliflozin did not reduce major adverse cardiac events but its trend in HF prevention was similar to that of the other agents.

Such a strong signal in preventing HF would suggest that use of SGLT2 inhibitors could be extended to the entire spectrum of HF, including established HF. However, there are a few caveats worth considering in these trials. First is the underrepresentation of patients with established HF, second is the lack of clarity with regard to the proportion of HFrEF vs HF with preserved EF (HFpEF), third is the possibility that guidelinedirected medical therapy for HFrEF could blunt some of the benefits of SGLT2 inhibitors, and fourth is the uncertainty of whether these benefits extended to HF patients without diabetes. Therefore, dedicated trials of SGLT2 inhibitors in preexisting HF were necessary, and dapagliflozin, empagliflozin, and sotagliflozin became the subject of clinical studies in patients with HFrEF and HFpEF. ${ }^{10-12,29,30}$ When investigators set out to determine the target population, a critical consideration was whether to include nondiabetic participants, and this important decision warranted a closer examination of the mechanism of CV benefits of SGLT2 inhibitors.

\section{Proposed mechanisms of benefit of SGLT2 inhibition in patients with $\mathrm{HF}$}

Because SGLT2 inhibitors were developed as diabetes medications, one proposed mechanism for their CV benefit is the reduction in hemoglobin A1c (HbA1c). The reduction in HbA1c with SGLT2 inhibitors however is modest, and in the aforementioned clinical trials, the difference between the 
Table 1. Key findings of SGLT2 inhibitors in CV safety trials

\begin{tabular}{|c|c|c|c|c|}
\hline & $\begin{array}{l}\text { EMPA-REG } \\
\text { OUTCOME }\end{array}$ & CANVAS Program & DECLARE-TIMI 58 & VERTIS CV \\
\hline HR, for MACE & $\begin{array}{c}0.86 ; 95 \% \mathrm{CI} \\
0.74-0.99 \\
P=0.04 \text { for } \\
\text { superiority }\end{array}$ & $\begin{array}{l}\text { 0.86; } 95 \% \mathrm{CI}, 0.75-0.97 ; P= \\
0.02 \text { for superiority }\end{array}$ & $0.93 ; 95 \% \mathrm{CI}, 0.84-1.03 ; P=0.17$ & $\begin{array}{l}0.97 ; 95.6 \% \mathrm{CI}, 0.85-1.11 ; P<0.001 \\
\quad \text { for noninferiority }\end{array}$ \\
\hline HR, for HF hospitalization & $\begin{array}{c}0.65 ; 95 \% \mathrm{CI} \\
0.50-0.85 \\
P=0.002\end{array}$ & $0.67 ; 95 \%$ CI, $0.52-0.87$ & $0.73 ; 95 \%$ CI, $0.61-0.88$ & $0.70 ; 95 \%$ CI, 0.54-0.90 \\
\hline $\begin{array}{l}\text { Percentage of patients with } \mathrm{HF} \\
\text { at baseline }\end{array}$ & $10 \%$ & $14 \%$ & $10 \%$ & $24 \%$ \\
\hline
\end{tabular}

CANVAS, Canagliflozin Cardiovascular Assessment Study; CI, confidence interval; CV, cardiovascular; DECLARE-TIMI 58, Dapagliflozin Effect on Cardiovascular Events-Thrombolysis in Myocardial Infarction 58; EMPA-REG OUTCOME, Empagliflozin Cardiovascular Outcome Event Trial in Type 2 Diabetes Mellitus Patients - Removing Excess Glucose; HF, heart failure; HR, hazard ratio; MACE, major adverse cardiac events; SGLT2, sodium glucose cotransporter 2; VERTIS CV, Evaluation or Ertugliflozin Efficacy and Safety Cardiovascular Outcomes Trial.

study drugs and placebo decreased over the trial duration (Fig. 2). Furthermore, any clinical benefit of reducing serum glucose should lag behind the reduction in HbAlc, but in these trials, the reduction in HF events was almost instantaneous, occurring within a few weeks, and suggesting that factors other than glucose reduction were responsible for these clinical benefits (Fig. 1).

Weight loss because of osmotic diuresis with SGLT2 inhibitors has been observed, but loop diuretics produce greater volume loss without translating into such important clinical benefits. ${ }^{31}$ Clinical gains from a reduction in visceral fat or improvement in BP by SGLT2 inhibitors would unlikely to be so early. ${ }^{32}$

Because the effects mentioned previously do not fully explain the magnitude nor the early timing of clinical gains observed in these trials, other theories have been proposed. One is on the basis of the evidence that these agents are ketogenic and ketone bodies are theorized to be a more efficient fuel for the failing heart. ${ }^{33}$ Another theory relates to the sodium hydrogen exchanger (NHE), which is expressed in the

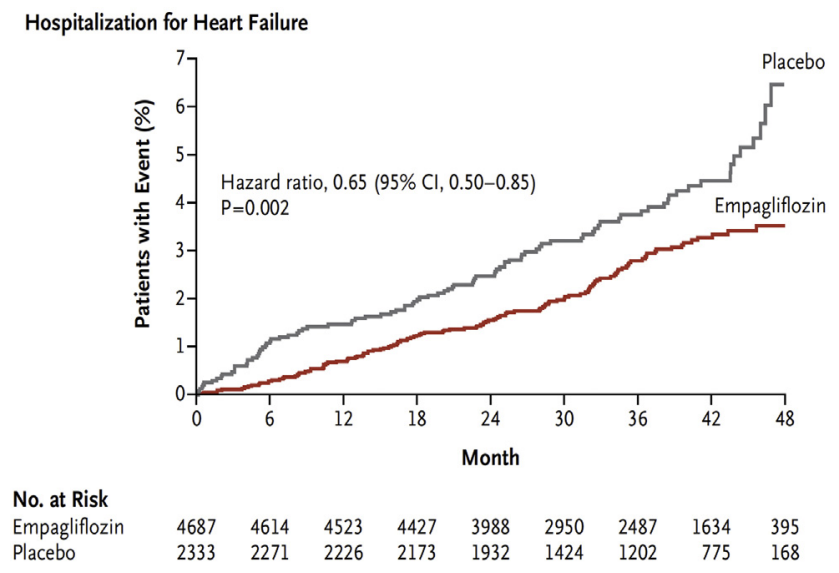

Figure 1. Cumulative incidence of heart failure hospitalization in Empagliflozin Cardiovascular Outcome Event Trial in Type 2 Diabetes Mellitus Patients - Removing Excess Glucose (EMPA-REG OUTCOME). Cl, confidence interval. From Zinman B., Wanner C., Lachin J.M. et al., Empagliflozin, Cardiovascular Outcomes, and Mortality in Type 2 Diabetes, N Engl J Med 373, 2015, pp. 2117-2128. Copyright (c) 2015 Massachusetts Medical Society. Reprinted with permission from Massachusetts Medical Society. heart and the kidney, and its increased activity in patients with HF leads to intracellular calcium accumulation. ${ }^{34}$ A previous attempt at selectively blocking the NHE using cariporide resulted in impressive clinical gains after coronary artery bypass surgery, and there is evidence that SGLT2 inhibitors also block the NHE. ${ }^{35}$ Another recent theory relates to a starvation stress response, which is blunted in diabetic patients with HF, because diabetes is a state of energy oversupply and SGLT2 inhibitors mimic a state of energy deprivation and therefore activate this protective transcription program. ${ }^{31,36}$

Regardless of the underlying mechanism, ample evidence suggests that the effects of SGLT2 inhibitors are pleiotropic and independent of blood glucose reduction, prompting investigators to include nondiabetic participants in trials of dapagliflozin and empagliflozin in patients with HFrEF and those with HFpEF.

\section{Evidence in patients with established $\mathrm{HF}$}

Three SGLT2 inhibitor trials in patients with HFrEF have been published. ${ }^{10-12}$ In the dapagliflozin and empagliflozin trials, investigators drew upon their experience from the PARADIGM-HF study, accounting for several similarities between their study designs (Table 2). In the Dapagliflozin and Prevention of Adverse Outcomes in Heart Failure (DAPA-HF) trial, 4744 patients were randomized to a fixed of dapagliflozin $10 \mathrm{mg}$ vs matched placebo without an uptitration or a run-in phase. Similar to PARADIGM-HF, patients were included if they had stable ambulatory chronic HF, with New York Heart Association (NYHA) functional class II-IV, left ventricular EF (LVEF) $\leq 40 \%$, and NT-proBNP of at least $\geq 400 \mathrm{pg} / \mathrm{mL}$. Patients were excluded if they had symptomatic hypotension or a systolic BP (SBP) $<95 \mathrm{~mm} \mathrm{Hg}$, an estimated glomerular filtration rate $\left(\right.$ eGFR) $<30 \mathrm{~mL} / \mathrm{min} / 1.73 \mathrm{~m}^{2}$, if they were hospitalized within 4 weeks for HF, or if they had type 1 diabetes. The study protocol provided guidance with regard to dose reduction of insulin and sulfonylureas if the HbAlc was $<7 \%$ at randomization.

As a result, the characteristics of patients included in the trial were strikingly similar to those in PARADIGM-HF. NYHA functional class II accounted for approximately twothirds of these patients, and NYHA functional class IV were under-represented. Importantly, more than half of patients were nondiabetic, giving the trial the statistical power for a prespecified analysis of an interaction between its primary 


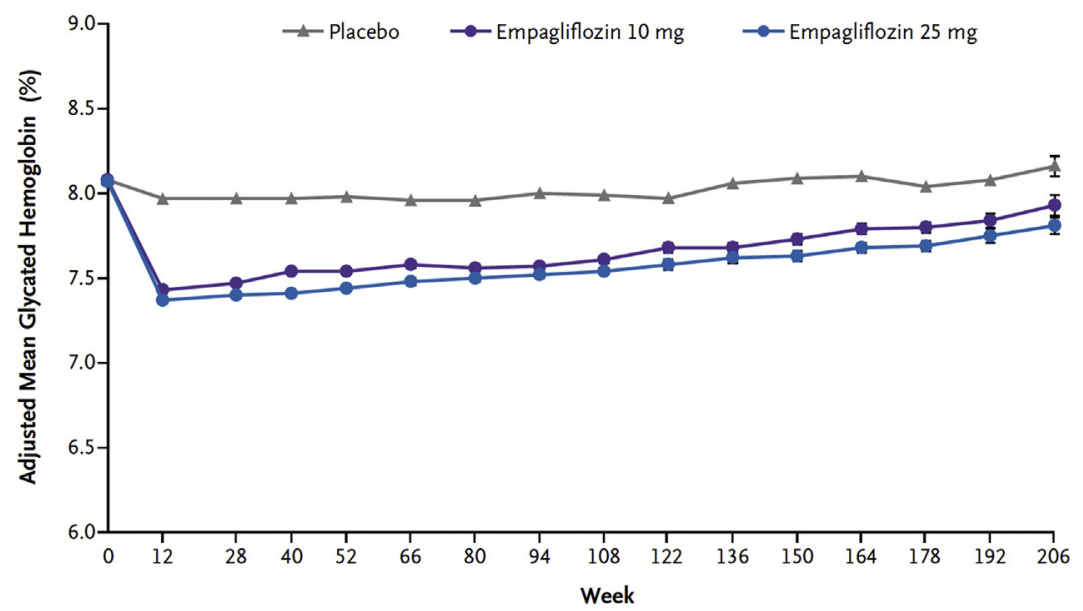

$\begin{array}{lllllllllllllllll}\text { No. at Risk } & & & & & & & & & & & & & & \\ \text { Placebo } & 2294 & 2272 & 2188 & 2133 & 2113 & 2063 & 2008 & 1967 & 1741 & 1456 & 1241 & 1109 & 962 & 705 & 420 & 151 \\ \text { Empagliflozin 10 mg } & 2296 & 2272 & 2218 & 2150 & 2155 & 2108 & 2072 & 2058 & 1805 & 1520 & 1297 & 1164 & 1006 & 749 & 488 & 170 \\ \text { Empagliflozin 25 mg } & 2296 & 2280 & 2212 & 2152 & 2150 & 2115 & 2080 & 2044 & 1842 & 1540 & 1327 & 1190 & 1043 & 795 & 498 & 195\end{array}$

Figure 2. Hemoglobin A1c levels across study groups in Empagliflozin Cardiovascular Outcome Event Trial in Type 2 Diabetes Mellitus Patients Removing Excess Glucose (EMPA-REG OUTCOME). From Zinman B., Wanner C., Lachin J.M. et al., Empagliflozin, Cardiovascular Outcomes, and Mortality in Type 2 Diabetes, N Engl J Med 373, 2015, pp. 2117-2128. Copyright (C 2015 Massachusetts Medical Society. Reprinted with permission from Massachusetts Medical Society.

outcome and diabetes status. Background medical therapy was excellent in both groups, including a high utilization rate of mineralocorticoid receptor antagonists. The use of sacubitril/ valsartan was unsurprisingly low (11\%), because the trial started soon after regulatory approval for sacubitril/valsartan.

With regard to the results, the primary outcome, a composite of CV death, unplanned HF hospitalization, or an urgent visit for intravenous therapy, was reduced by $26 \%$, a reduction that was highly statistically significant (HR, 0.74; 95\% CI, 0.65-0.85; $P<0.001$ ). The absolute risk reduction was $4.9 \%$, and the number needed to treat (NNT) to prevent one composite event was 21 after a median follow-up of 18 months. The survival curves separated early, and the incidence of a composite event rate in the placebo arm approximated that seen in the enalapril arm of PARADIGM-HF, further supporting the similarity between the 2 study populations. With regard to the individual components of the primary composite end point, $\mathrm{HF}$ events were reduced by 30\% (HR, 0.70; 95\% CI, 0.59 0.83 ; $P$ value not applicable) and CV death was reduced by $18 \%$ (HR, 0.82; $95 \%$ CI, 0.69-0.98; $P$ value NA). The key secondary end points of quality of life measured using the Kansas City Cardiomyopathy Questionnaire improved in favour of dapagliflozin (total symptom score $6.1 \pm 18.6$ vs $3.3 \pm 19.2 ; P<0.001)$, and all-cause mortality was reduced by $17 \%$ (HR, $0.83 ; 95 \%$ CI, $0.71-0.97 ; P$ value NA).

There was no signal for any interaction with the presence or absence of diabetes, and the curves with regard to the primary composite end point separated identically in diabetic and nondiabetic participants. A subgroup analysis suggested that subjects with NYHA functional class III symptoms derived less benefit, but this was not congruent with other findings that showed that patients with EF below the median and those across the entire spectrum of NT-proBNP levels derived benefit. The lack of a biological plausibility for this interaction further suggested that it was a spurious finding. In a post hoc analysis of an interaction with background use of angiotensin receptor-neprilysin inhibitor, the point estimates with regard to the primary end point were similar, although the $\mathrm{CI}$ for the small number of patients receiving ARNI was wide, crossing the line of unity.

A few other observations are worth noting. There was a greater reduction in NT-proBNP from a baseline median of $1437 \mathrm{pg} / \mathrm{mL}(-196 \pm 2387 \mathrm{pg} / \mathrm{mL}$ vs $101 \pm 2944 \mathrm{pg} / \mathrm{mL}$; $P<0.001)$, a modest reduction in weight $(-0.88 \pm 3.86 \mathrm{~kg}$ vs $0.10 \pm 4.09 \mathrm{~kg} ; P<0.001)$, and SBP $(-1.92 \pm 14.92$ $\mathrm{mm} \mathrm{Hg}$ vs $-0.38 \pm 15.27 \mathrm{~mm} \mathrm{Hg} P=0.002)$ with dapagliflozin. This difference in SBP was less than the $3.2 \pm$ $0.4 \mathrm{~mm} \mathrm{Hg}$ reduction in SBP observed with sacubitril/valsartan compared with enalapril in PARADIGM-HF, and despite the lack of a head-to-head comparison between dapagliflozin and sacubitril/valsartan, detailed analyses of the BP effect of each agent suggest a better tolerability profile for dapagliflozin compared with sacubitril/valsartan with respect to BP. ${ }^{37,38}$ There was no difference in discontinuation rates in the 2 arms in DAPA-HF, and no difference in rates of hypoglycemia or diabetic ketoacidosis. Serious adverse events related to volume depletion were higher with dapagliflozin without reaching statistical significance.

The results of the Empagliflozin Outcome Trial in $\mathrm{Pa}$ tients With Chronic Heart Failure With Reduced Ejection Fraction (EMPEROR-Reduced) were recently published. ${ }^{11}$ Although the trial broadly had inclusion criteria similar to DAPA-HF, investigators intended to achieve an annual HF event rate of at least $15 \%$ and sought to enrich this trial with a higher-risk population who had a lower EF and a higher NTproBNP level compared with in DAPA-HF. This was achieved by requiring a history of $\mathrm{HF}$ hospitalization $<12$ months and NT-proBNP $\geq 1000 \mathrm{pg} / \mathrm{mL}$ for those with EF $31 \%-35 \%$, and $\geq 2500 \mathrm{pg} / \mathrm{mL}$ for those with EF $36 \%-40 \%$. The primary outcome was a composite of time to first CV death or HF hospitalization. The trial achieved its desired 
Table 2. Comparison of key recent HFrEF trials

\begin{tabular}{|c|c|c|c|c|c|c|}
\hline & PARADIGM-HF & DAPA-HF & $\begin{array}{l}\text { EMPEROR- } \\
\text { Reduced }\end{array}$ & SOLOIST-WHF & VICTORIA & GALACTIC-HF \\
\hline $\mathrm{N}$ & 8442 & 4744 & 3730 & 1222 & 5050 & 8256 \\
\hline \multicolumn{7}{|l|}{$\begin{array}{l}\text { Key trial design } \\
\text { features }\end{array}$} \\
\hline Intervention & $\begin{array}{l}\text { Sacubitril/valsartan } \\
200 \mathrm{mg} \text { BID vs } \\
\text { enalapril } 10 \mathrm{mg} \\
\text { BID }\end{array}$ & $\begin{array}{l}\text { Dapagliflozin } 10 \\
\text { mg daily vs } \\
\text { placebo }\end{array}$ & $\begin{array}{l}\text { Empagliflozin } 10 \\
\text { mg daily vs } \\
\text { placebo }\end{array}$ & $\begin{array}{l}\text { Sotagliflozin } 200 \mathrm{mg} \text { daily, up } \\
\text { to } 400 \mathrm{mg} \text { daily if tolerated } \\
\text { vs placebo }\end{array}$ & $\begin{array}{l}\text { Vericiguat } 10 \mathrm{mg} \text { daily vs } \\
\text { placebo }\end{array}$ & $\begin{array}{l}\text { Omecamtiv mecarbil } 25-50 \mathrm{mg} \\
\text { BID (guided by plasma } \\
\text { levels) vs placebo }\end{array}$ \\
\hline \multirow[t]{2}{*}{$\begin{array}{l}\text { Key inclusion } \\
\text { criteria }\end{array}$} & $\begin{array}{l}\text { NYHA II-IV, } \\
\quad \text { LVEF } \leq 40 \%\end{array}$ & $\begin{array}{l}\text { NYHA II-IV, } \\
\quad \text { LVEF } \leq 40 \%\end{array}$ & $\begin{array}{l}\text { NYHA II-IV, } \\
\quad \text { LVEF } \leq 40 \%\end{array}$ & $\begin{array}{l}\text { DM type } 2, \mathrm{HF} \text { diagnosis } \geq 3 \\
\text { months regardless of } \mathrm{EF}, \\
\text { hospitalized with HF treated } \\
\text { with I.V. diuretics }\end{array}$ & $\begin{array}{l}\text { NYHA II-IV, LVEF }<45 \%, \\
\text { HF hospitalization }<6 \\
\text { months or I.V. diuretics, } \\
\text { inpatients and outpatients }\end{array}$ & $\begin{array}{l}\text { NYHA II-IV, HF diagnosis for } \\
\geq 30 \text { days, LVEF } \leq 35 \%, \\
\text { inpatients and outpatients }\end{array}$ \\
\hline & $\begin{array}{l}\text { NT-proBNP } \geq \\
600 \mathrm{pg} / \mathrm{mL} \text { or } \geq \\
400 \mathrm{pg} / \mathrm{mL} \text { if } \\
\text { hospitalized for } \\
\text { HF within 1 } \\
\text { year }\end{array}$ & $\begin{array}{l}\text { NT-proBNP } \geq \\
600 \mathrm{pg} / \mathrm{mL} \text { or } \geq \\
400 \mathrm{pg} / \mathrm{mL} \text { if } \\
\text { hospitalized for } \\
\text { HF within } 1 \\
\text { year or } \geq 900 \\
\mathrm{pg} / \mathrm{mL} \text { if } \mathrm{AF}\end{array}$ & $\begin{array}{c}\mathrm{EF} \leq 30 \%: \mathrm{NT}- \\
\text { proBNP } \geq 600 \\
\mathrm{pg} / \mathrm{mL} \text { or } \geq \\
1200 \mathrm{pg} / \mathrm{mL} \text { if } \\
\mathrm{AF} \\
\text { EF } 31 \%-35 \%: \\
\mathrm{NT}-\mathrm{proBNP} \geq \\
1000 \mathrm{pg} / \mathrm{mL} \text { or } \\
\geq 2000 \mathrm{pg} / \mathrm{mL} \\
\text { if } \mathrm{AF} \\
\mathrm{EF} 36 \%-40 \%: \\
\mathrm{NT}-\mathrm{proBNP} \geq \\
2500 \mathrm{pg} / \mathrm{mL} \text { or } \\
\geq 5000 \text { if AF }\end{array}$ & $\begin{array}{l}\text { NT-proBNP } \geq 600 \mathrm{pg} / \mathrm{mL} \text { or } \\
\quad \geq 1800 \mathrm{pg} / \mathrm{mL} \text { if } \mathrm{AF}\end{array}$ & $\begin{array}{l}\text { NT-proBNP } \geq 1000 \mathrm{pg} / \mathrm{mL} \\
\text { or } \geq 1600 \mathrm{pg} / \mathrm{mL} \text { if AF }\end{array}$ & $\begin{array}{l}\text { NT-proBNP } \geq 400 \mathrm{pg} / \mathrm{mL} \text { or } \\
\quad \geq 1200 \mathrm{pg} / \mathrm{mL} \text { if AF }\end{array}$ \\
\hline $\begin{array}{l}\text { Key exclusion } \\
\text { criteria }\end{array}$ & $\begin{array}{l}\text { ADHF, } \\
\text { symptomatic } \\
\text { hypotension or } \\
\mathrm{SBP}<100 \mathrm{~mm} \\
\mathrm{Hg} \text { at screening } \\
\text { or }<95 \mathrm{~mm} \mathrm{Hg} \\
\text { at } \\
\text { randomization, } \\
\text { eGFR }<30 \mathrm{~mL} / \\
\mathrm{min} / 1.73 \mathrm{~m}^{2}\end{array}$ & $\begin{array}{l}\text { ADHF, } \\
\text { symptomatic } \\
\text { hypotension or } \\
\mathrm{SBP}<95 \mathrm{~mm} \\
\mathrm{Hg}, \text { eGFR }<30 \\
\mathrm{~mL} / \mathrm{min} / 1.73 \\
\mathrm{~m}^{2}, \text { DM type } 1\end{array}$ & $\begin{array}{l}\text { ADHF, } \\
\text { symptomatic } \\
\text { hypotension or } \\
\mathrm{SBP}<100 \mathrm{~mm} \\
\mathrm{Hg}, \text { eGFR }<20 \\
\mathrm{~mL} / \mathrm{min} / 1.73 \\
\mathrm{~m}^{2}\end{array}$ & $\begin{array}{l}\text { Unstable ADHF, SBP }<100 \\
\text { mm Hg, I.V. diuretics, I.V. } \\
\text { inotrope, or I.V. vasodilator } \\
\text { (except nitrates) within } 2 \\
\text { days of randomization, } \\
\text { mechanical ventilation } / \mathrm{O}_{2} \\
\text { therapy within } 24 \text { hours }\end{array}$ & $\begin{array}{l}\text { Unstable ADHF, SBP }<100 \\
\mathrm{~mm} \mathrm{Hg}, \text { eGFR }<15 \mathrm{~mL} / \\
\mathrm{min} / 1.73 \mathrm{~m}^{2}\end{array}$ & $\begin{array}{l}\text { Unstable ADHF, } \mathrm{SBP}<85 \\
\mathrm{~mm} \mathrm{Hg}, \mathrm{GGFR}<20 \mathrm{~mL} / \\
\mathrm{min} / 1.73 \mathrm{~m}^{2}, \mathrm{I} . \mathrm{V} \text {. inotrope } \\
\leq 3 \text { days, I.V. diuretic, } \\
\text { supplemental } \mathrm{O}_{2} \text {, or } \\
\text { noninvasive ventilation } \leq \\
12 \text { hours }\end{array}$ \\
\hline Primary outcome & $\begin{array}{l}\mathrm{CV} \text { death or a first } \\
\text { hospitalization } \\
\text { for HF }\end{array}$ & $\begin{array}{l}\text { CV death, or } \\
\text { unplanned HF } \\
\text { hospitalization, } \\
\text { or urgent visit } \\
\text { for I.V. therapy } \\
\text { for HF }\end{array}$ & $\begin{array}{l}\text { Time to first CV } \\
\text { death or HF } \\
\text { hospitalization }\end{array}$ & $\begin{array}{l}\text { Total number of deaths for CV } \\
\text { causes and hospitalizations } \\
\text { and urgent visit for HF (first } \\
\text { and subsequent events) }\end{array}$ & $\begin{array}{l}\text { CV death or first HF } \\
\text { hospitalization }\end{array}$ & $\begin{array}{l}\text { Time to first CV death or an } \\
\text { HF event, defined as urgent } \\
\text { clinic or ED visit or } \\
\text { hospitalization with HF that } \\
\text { resulted in intensification of } \\
\text { HF therapy beyond oral } \\
\text { diuretic }\end{array}$ \\
\hline \multicolumn{7}{|l|}{ Baseline Characteristics } \\
\hline Mean age, years & 64 & 66 & 67 & 70 & 67 & 65 \\
\hline Female sex, \% & 22 & 23 & 24 & 34 & 24 & 21 \\
\hline NYHA II/III & $70 / 24$ & $68 / 32$ & $75 / 24$ & - & $59 / 40$ & $53 / 44$ \\
\hline $\begin{array}{l}\text { Mean or (median) } \\
\text { EF, \% }\end{array}$ & 30 & 31 & 27 & (35) & 29 & 27 \\
\hline $\begin{array}{l}\text { Median NT- } \\
\text { proBNP, pg/mL }\end{array}$ & 1615 & 1437 & 1907 & 1779 & 2812 & 2134 \\
\hline
\end{tabular}




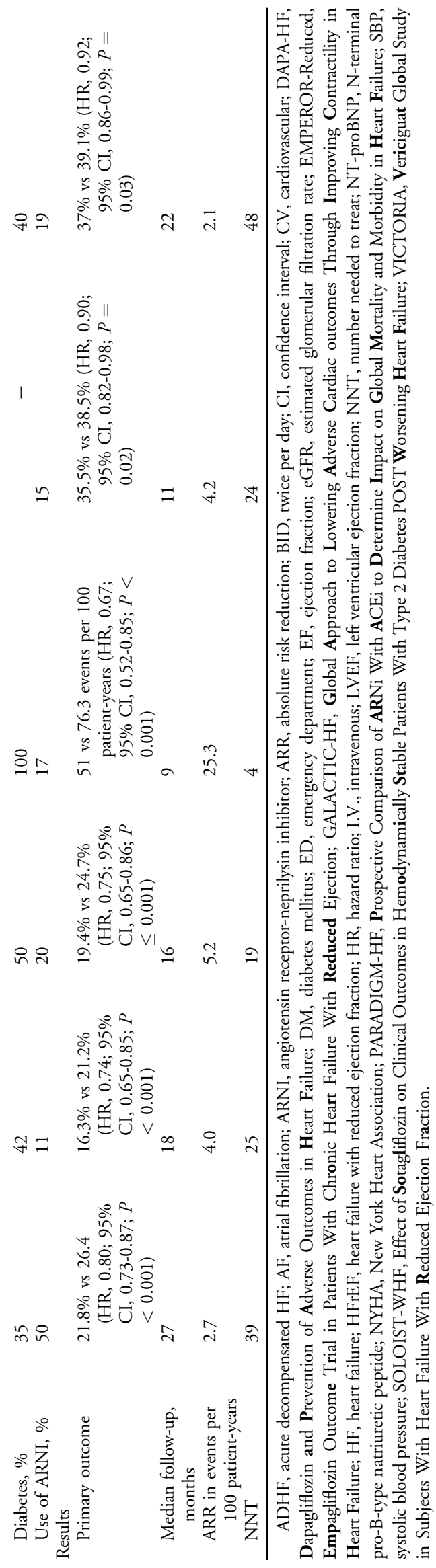

events after enrolling 3730 patients, randomized to empagliflozin $10 \mathrm{mg}$ vs placebo. After a median follow-up of 16 months, the primary outcome was reduced in the empagliflozin arm by $25 \%$ (HR, 0.75; 95\% CI, 0.65-0.86; $P<0.001)$, translating to an NNT of 19 to prevent 1 primary event. This reduction was primarily driven by a reduction in time to first $\mathrm{HF}$ hospitalization (HR, 0.69; 95\% CI, $0.59-0.81 ; P$ value NA), and although the reduction in $\mathrm{CV}$ death (HR, 0.92; 95\% CI, 0.75-1.12) was less robust than that with dapagliflozin in DAPA-HF, data in the HF prevention setting had shown a greater reduction in $\mathrm{CV}$ death with empagliflozin compared with dapagliflozin, with the implication that it is unlikely that 1 agent is superior with regard to effect on mortality. Empagliflozin also reduced the rate of decline in eGFR compared with placebo, with an annual between group difference of $1.73 \mathrm{~mL} / \mathrm{min} / 1.73 \mathrm{~m}^{2}$ (95\% CI, 1.10-2.37; $P<0.001$ ).

Similar to dapagliflozin, the benefits of empagliflozin on the primary outcome were observed in diabetic and nondiabetic participants. A relatively higher proportion of patients was receiving background therapy with sacubitril/valsartan $(18.3 \%)$ than in DAPA-HF, and in a prespecified subgroup analysis, the reduction in the primary outcome occurred regardless of background use of ARNI. The reduction in NTproBNP, weight, and SBP $(-2.4 \pm 0.4 \mathrm{~mm} \mathrm{Hg}$ vs $-1.7 \pm$ $0.4 \mathrm{~mm} \mathrm{Hg} ; P$ value NA) were comparable with those observed with dapagliflozin in DAPA-HF.

Although neither trial was individually powered to assess effect on $\mathrm{CV}$ death or all-cause mortality, in a meta-analysis of both trials a $13 \%$ reduction in all-cause mortality $(P=0.018)$ and $14 \%$ reduction in $\mathrm{CV}$ death $(P=0.027)$ was estimated. The pooled benefits extended to nondiabetic patients and those treated with ARNI. ${ }^{39}$

The third trial tested sotagliflozin, an SGLT2 inhibitor with some gastrointestinal SGLT1 inhibition. ${ }^{12}$ The Effect of Sotagliflozin on Clinical Outcomes in Hemodynamically Stable Patients With Type 2 Diabetes POST Worsening Heart Failure (SOLOIST-WHF) trial examined the efficacy and safety of SGLT2/1 inhibition after a recent episode of decompensated $\mathrm{HF}$ in diabetic patients diagnosed with $\mathrm{HF}$ for $\geq 3$ months. Patients with HFrEF and HFpEF were recruited during an HF hospitalization, provided they had achieved clinical stability, defined as $\mathrm{SBP} \geq 100 \mathrm{~mm} \mathrm{Hg}$ and no ongoing use of intravenous diuretics, inotropes, or oxygen therapy. Because of loss of funding from the sponsor, the trial was terminated early, diminishing its power and requiring a change of its primary end point to the total number of $\mathrm{CV}$ deaths and hospitalizations and urgent visits for HF on the basis of investigator-defined events. The trial enrolled 1222 patients, 256 of whom had EF $\geq 50 \%$, and randomized them during hospitalization (48.8\%) or within 3 days after discharge $(51.2 \%)$ to sotagliflozin $200 \mathrm{mg}$ once daily, up to $400 \mathrm{mg}$ once daily, vs placebo. After a median follow-up of 9 months, sotagliflozin reduced the composite primary end point compared with placebo (HR, 0.67; 95\% CI, 0.52-0.85; $P<0.001$ ), driven by a reduction in hospitalizations and urgent visits for $\mathrm{HF}$ (HR, 0.64; 95\% CI, 0.49-0.83; $P<0.001)$. There was no heterogeneity among subgroups, including across ranges of EF, but the number of patients with HFpEF was too small to draw definite conclusions. Severe hypoglycemia was more common with sotagliflozin compared 
with placebo $(1.5 \%$ vs $0.3 \%)$. Despite its early termination, the trial convincingly showed benefits of early initiation of an SGLT2/1 inhibitor in patients with worsening HF. No clear conclusions, however, can be drawn regarding the incremental value of SGLT1 inhibition, and whether the benefit of upstream use of sotagliflozin is specific to this agent or whether it is a class effect will have to await the conclusion of ongoing SGLT2 inhibitor studies. Nevertheless, the weight of evidence thus far favours a class effect.

\section{Current status and future directions}

Taken together, DAPA-HF, EMPEROR-Reduced, and SOLOIST-WHF provide consistent evidence that as a class, the SGLT2 inhibitors produce substantial additive survival benefits in patients with HF, with or without diabetes. On May 5, 2020, and before the publication of EMPEROR-Reduced and SOLOIST-WHF, the FDA approved dapagliflozin for the treatment of symptomatic HFrEF, regardless of presence or absence of diabetes. ${ }^{16}$ The United States therefore became the first jurisdiction to do so, transitioning the drug from being a diabetes-only medication to becoming a HF medication, and continuing the trend of other HFrEF therapies that were developed for other indications but eventually became fullfledged HF therapies. It appears only logical that this recommendation will be extended in time to other agents in this class.

The SGLT2 inhibitor trials were published in quick succession and tested agents as add-on treatments in patients with chronic HF managed according to the standard of care available at the time of those trials. Although the trials are a remarkable step forward, questions remain with respect to the optimal sequence of initiating SGLT2 inhibitors amid other established HFrEF therapies and across more diverse clinical settings such as new-onset treatment-naive HF or severe renal impairment. Updated guidelines on this subject are due, and recommendations espousing earlier introduction of ARNI, upfront without prerequisite ACEI/ARB in patients hospitalized with de novo HF, have prioritized early risk mitigation. ${ }^{40}$ This principle might also justify early initiation of SGLT2 inhibitors, now a foundational HFrEF therapy, to avoid their delayed uptake under the classic paradigm of stepwise therapy. ${ }^{41}$ Nevertheless, early use of SGLT2 inhibitors concomitant with other agents has to be balanced against expense, polypharmacy, interference with uptitration of existing agents and the need for careful monitoring.

We therefore advocate early initiation of SGLT2 inhibitors in $3 \mathrm{HFrEF}$ groups of interest. The first is patients with elevated risk, whose natriuretic peptide levels match the inclusion natriuretic peptide levels in clinical trials, or those who have suffered an HF hospitalization, to achieve robust and prompt risk reduction. The second is diabetic patients with HFrEF, regardless of symptoms, because of the strong supportive CV outcomes data in diabetes trials. The third is patients with new-onset HFrEF and SBP $<95$ $\mathrm{mm} \mathrm{Hg}$, a population excluded from contemporary trials, but who are more likely to tolerate SGLT2 inhibitors upfront because of their lesser effect on BP compared with sacubitril/valsartan (Fig. 3). These proposed strategies should ideally be tested for safety and cost effectiveness within dedicated studies.
HFrEF patients routinely receive multiple therapies for $\mathrm{HF}$ and comorbidities, risking adverse interactions and poor adherence. Discontinuation of nonessential therapies limits polypharmacy. Because of the risk of volume depletion, loop diuretic dosing should be reevaluated in euvolemic patients, and SGLT2 inhibitors should be deferred in hypovolemic patients, or withheld before major surgery. Concomitant insulin or sulfonylureas might require downtitration especially if the HbAlc is at target. Coordinating care in select cases with a diabetes specialist for safe SGLT2 inhibitor initiation might introduce treatment inertia, but effective multidisciplinary collaborations could overcome such barriers. Genital mycotic infections, although a common side effect, do not require cessation of SGLT2 inhibitors. ${ }^{19,41}$

SGLT2 inhibitors can reduce the glomerular filtration rate in the short term but have a favourable long-term effect on renal outcomes. ${ }^{19}$ The inclusion eGFR in most HF trials was $>30 \mathrm{~mL} / \mathrm{min} / 1.73 \mathrm{~m}^{2}$, and in the case of EMPERORReduced, a cutoff value of $\geq 20 \mathrm{~mL} / \mathrm{min} / 1.73 \mathrm{~m}^{2}$ was significantly below the manufacturer's recommendation, with no signal for harm. ${ }^{41}$ Because treatment with ARNI can now be considered below the inclusion eGFR limit of $<30$ $\mathrm{mL} / \mathrm{min} / 1.73 \mathrm{~m}^{2}$ in PARADIGM-HF, we speculate future recommendations to provide some latitude with regard to initiating SGLT2 inhibitors at eGFR values below those in clinical trials. ${ }^{40}$

On the basis of the available evidence, SGLT2 inhibitors have become another cornerstone in managing HFrEF. The up and coming iteration of HF guidelines are expected to provide practical guidance on use of these drugs in light of the concluded trials.

\section{Soluble Guanylate Cyclase Stimulation}

\section{Mechanism of action}

The impetus for developing this class of agents emanated from the discovery of the nitric oxide (NO)cyclic guanosine monophosphate (cGMP) pathway and its critical role in $\mathrm{CV}$ physiology, a discovery that led to awarding the Nobel prize in 1998 to the scientists credited for their work. ${ }^{42}$

It has been recognized that NO bioavailability is reduced in both phenotypes of HF. Such reduced activity leads to diminished cGMP and protein kinase G activity, which ultimately promotes hypertrophy, arterial stiffness, and titin stiffness. ${ }^{43,44}$

Therefore, there have been many attempts to restore the NO-cGMP balance in HF, achieving mixed results. One successful example is the use of isosorbide dinitrate with hydralazine in the African American population with HFrEF, resulting in important reductions in mortality. ${ }^{45}$ Another successful example is the augmentation of natriuretic peptides with neprilysin inhibition, because natriuretic peptides interact with cell surface receptors that further activate cGMP through downstream NO-independent mechanisms. ${ }^{46}$ However, efforts at restoring NO-cGMP through isosorbide mononitrate, phosphodiesterase 5 inhibition, and inorganic nitrites in HFpEF have been disappointing. ${ }^{47-49}$ 


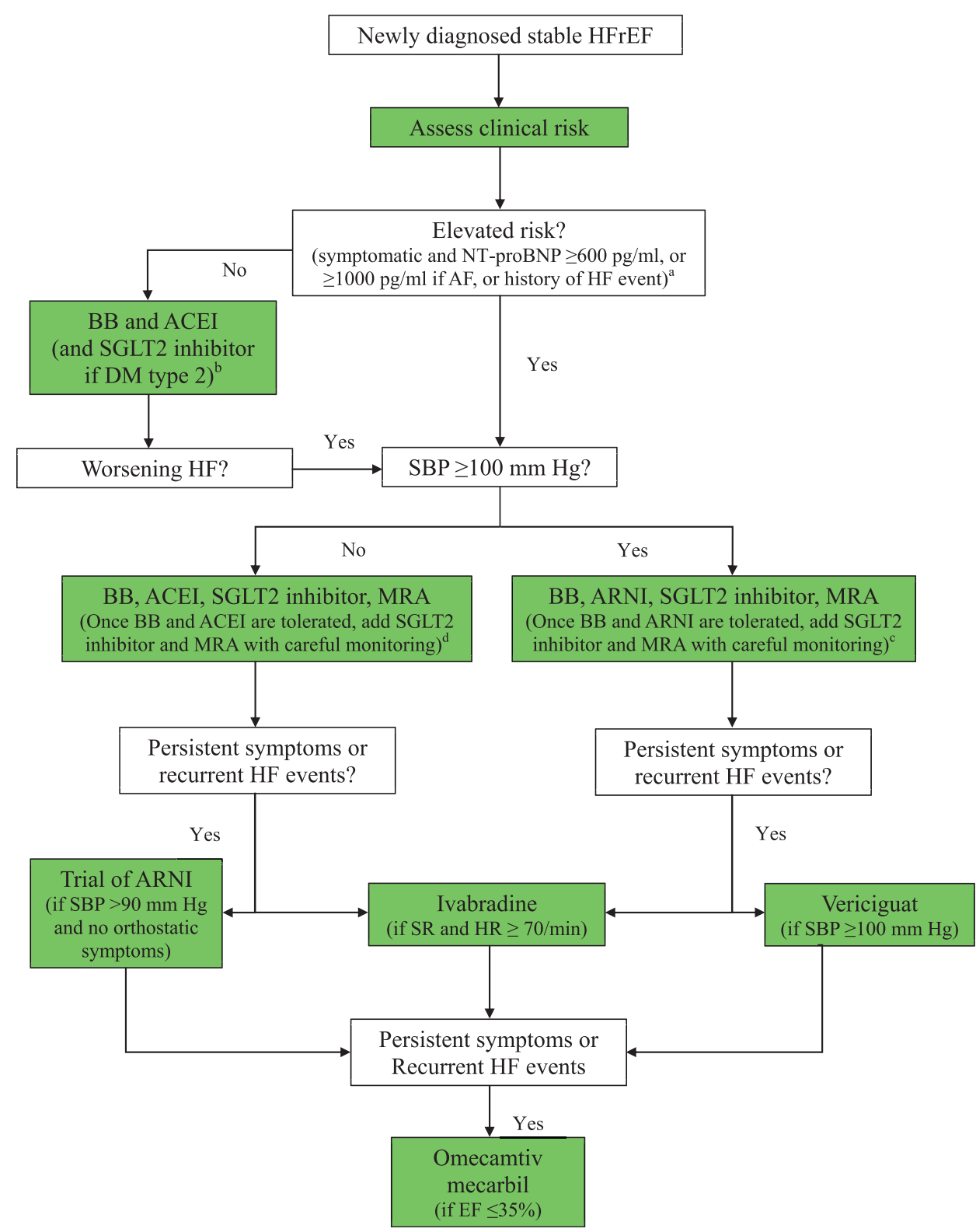

Figure 3. Algorithm for integrating novel therapies into heart failure with reduced ejection fraction (HFrEF) pharmacologic management. ACEI, angiotensin converting enzyme inhibitor; ADHF, acute decompensated HF; AF, atrial fibrillation; ARNI, angiotensin receptor-neprilysin inhibitor; BB, $\beta$-blocker; BP, blood pressure; CRT/D, cardiac resynchronization therapy/defibrillator; DM, diabetes mellitus; ED, emergency department; EF, ejection fraction; HF, heart failure; HR, heart rate; MRA, mineralocortocoid receptor antagonist; NNT, number needed to treat; NP, natriuretic peptide; NT-proBNP, N-terminal pro-B-type natriuretic peptide; OM, omecamtiv mecarbil; SBP, systolic blood pressure; SGLT2, sodium glucose cotransporter 2; SR, sinus rhythm. ${ }^{a}$ Elevated risk is defined by the presence of HF symptoms and NP elevation or a history of HF event regardless of NP level. The choice of NP cutoff in ambulatory patients is on the basis of inclusion criteria of recent HFrEF studies because such patients enriched the trials with high event rates and are most likely to benefit from quadruple therapy (BB, ARNI/ACEI, SGLT2 inhibitor, and MRA). An HF event is also a marker of elevated risk, and because a low NP level does not always exclude elevated risk (eg, obese patients), no NP values are suggested to qualify for quadruple therapy in case of an HF event. ${ }^{b}$ Patients without an elevated risk might respond to BB and ACEI therapy alone. This strategy balances the therapeutic efficacy of the established combination of BB and ACEl with cost effectiveness in low-risk patients. ${ }^{\circ}$ Quadruple therapy for patients with SBP $\geq 100 \mathrm{~mm} \mathrm{Hg}$ and elevated risk may be started upfront to reduce risk promptly. We suggest starting BB and ARNI, and when tolerated, start an SGLT2 inhibitor and MRA without awaiting a clinical response. There should be no diuretic dose escalation or use of inotropes within 24 hours for hospitalized patients before ARNI initiation. Although this approach departs from existing guideline recommendation of triple therapy, it prioritizes prompt risk reduction and extrapolates benefits of upfront ARNI and add-on SGLT2 inhibition in ADHF to the ambulatory setting. If symptoms persist, ivabradine and vericiguat could be used together. Patients with persistence of symptoms despite use of those agents might qualify for OM. The greater effect size of vericiguat in Vericiguat Global Study in Subjects With Heart Failure With Reduced Ejection Fraction (VICTORIA), the smaller NNT, and the need for therapeutic monitoring of OM were taken into consideration in selecting the order of preference between vericiguat and OM. ${ }^{d}$ Patients with SBP $<100 \mathrm{~mm} \mathrm{Hg}$ should receive quadruple therapy but with an ACEI, because of the availability of short-acting ACEI that might be better tolerated BP-wise. If symptoms persist despite quadruple therapy, ARNI can be attempted provided the SBP > $90 \mathrm{~mm} \mathrm{Hg}$ without orthostatic symptoms. 
NO activates cGMP by interacting with an intermediary molecule called soluble guanylate cyclase. Cinaciguat, riociguat, and vericiguat are examples of orally bioavailable agents that interact with a receptor on soluble guanylate cyclase and stabilize the enzyme in its active configuration, yielding an activation mechanism that is synergistic yet independent of NO. ${ }^{50,51}$

\section{Evidence in patients with $\mathrm{HF}$}

Several preclinical trials and phase I and II studies laid the basis for use of vericiguat in patients with HF. ${ }^{52,53}$ The Soluble Guanylate Cyclase Stimulator in Heart Failure Patients With Reduced Ejection Fraction Study (SOCRATESREDUCED) was a dose-identifying trial of vericiguat in highrisk HF patients. It did not meet its primary efficacy end point of reducing NT-proBNP at 12 weeks, but a prespecified secondary analysis suggested a dose-response relationship, with the highest dose of $10 \mathrm{mg}$ producing the greatest reduction in NT-proBNP.

This study provided the basis for the phase III VICTORIA trial, the largest trial to date in this class $(\mathrm{N}=5050)$, which examined the efficacy and safety of vericiguat $10 \mathrm{mg}$ vs placebo in high-risk HF patients.' Patients with NYHA functional class II-IV HF and LVEF $<45 \%$ were included if they had a HF hospitalization within 6 months or were receiving intravenous diuretics, with elevated NT-proBNP. Key exclusion criteria were SBP $<100 \mathrm{~mm} \mathrm{Hg}$, eGFR $<15 \mathrm{~mL} / \mathrm{min} /$ $1.73 \mathrm{~m}^{2}$, or concomitant use of long-acting nitrates or phosphodiesterase 5 inhibitors. The trial did not have a run-in phase and vericiguat was uptitrated within 3 months.

Baseline characteristics of patients reflected the high-risk inclusion criteria. Eighty-seven percent had a history of HF hospitalization within 6 months and there was a greater proportion of those with NYHA functional class III-IV (41\%) compared with patients in PARADIGM-HF, DAPA-HF, and EMPEROR-Reduced (Table 2). Median NT-proBNP level was higher compared with those trials. The rate of use of sacubitril/valsartan was $15 \%$, and although unreported, the rate of background therapy with SGLT2 inhibition was likely low.

Vericiguat reduced the composite of $\mathrm{CV}$ death or first $\mathrm{HF}$ hospitalization by $10 \%(\mathrm{HR}, 0.90 ; 95 \% \mathrm{CI}, 0.82-0.98 ; P=$ 0.02 ). There was no reduction in $\mathrm{CV}$ death alone, so the benefit was driven by a reduction in the time to first $\mathrm{HF}$ hospitalization (HR, 0.90; 95\% CI, 0.81-1.00; $P$ value NA). Despite an expected decrease in BP, there was no statistically significant difference in occurrence of hypotension or syncope $(9.1 \%$ vs $7.9 \% ; P=0.12$ and $4.0 \%$ vs $3.5 \% ; P=0.30$, respectively). Vericiguat did not affect renal function or electrolytes, but there was an unexplained increased risk of anemia.

Although the effect size of vericiguat on the primary outcome might not appear to be much, it ought to be considered in the context of the high event rate. The higher the event rate at baseline, the more closely relative risk reduction tracks absolute risk reduction, and in this study, the $10 \%$ relative reduction translated to a reduction of 4.2 events per 100 patient-years. The corresponding NNT was 24 to prevent 1 composite event after 10.8 months, and although the annualized absolute risk reduction is similar to that in DAPA-HF and higher than in PARADIGM-HF, caution is required when trials with different populations are compared, because it is possible that if either dapagliflozin or sacubitril/ valsartan were studied in a population similar to that in the VICTORIA trial, the reduction in absolute risk would have been greater with either agent. Such was the case with enalapril, which had a greater treatment effect in the high-risk population in the Cooperative North Scandinavian Enalapril Survival Study (CONSENSUS) compared with its effect in the lower-risk population in the Studies of Left Ventricular Dysfunction (SOLVD-Treatment) trial. ${ }^{54-56}$

\section{Current status and future directions}

It is possible that a larger treatment effect of vericiguat would have been observed with a longer duration of followup, but on the basis of the results of the VICTORIA trial, which showed primarily a reduction in HF hospitalization, vericiguat could be poised to becoming an ancillary secondline treatment for high-risk individuals.

Because of its unique mechanism of action, vericiguat represents another option for treating high-risk patients, particularly for those who are poor candidates for standard therapies because of severe renal or electrolyte disturbances (Fig. 3).

\section{Cardiac Myosin Activation}

\section{Mechanism of action}

Omecamtiv mecarbil (OM) is currently the only medication in the novel category of direct myosin activators available for clinical evaluation. ${ }^{57}$ The idea behind this class is to address impaired contractility, the fundamental defect in HFrEF.

OM was developed more than a decade ago after screening approximately 400,000 molecules on reconstituted sarcomere, then optimizing the candidate molecule for oral delivery and cardiac selectivity. It differs from conventional inotropes, which stimulate cyclic adenosine monophosphate and in turn open L-type calcium channels and ryanodine receptors, causing intracellular hypercalcemia. Conventional inotropes therefore increase heart rate and myocardial oxygen demand, and through these deleterious effects they increase mortality. ${ }^{58}$

OM directly activates myosin by priming myosin heads in the pre-power stroke phase, to engage in greater numbers with actin filaments. Its action is akin to having "more hands to pull on a rope." It therefore improves contractility without interfering with calcium homeostasis or increasing myocardial oxygen demand. This class is therefore more aptly described as a myotrope as opposed to a calcitrope, a term reserved for conventional inotropes. ${ }^{58}$

\section{Evidence in patients with $\mathrm{HF}$}

Animal studies followed by phase I and phase II human trials of OM provided the safety and efficacy signal for larger clinical trials. ${ }^{5,59}$ In the Chronic Oral Study of Myosin Activation to Increase Contractility in Heart Failure (COSMIC-HF), OM improved the systolic ejection time $(P<$ 0.001 ), a key biologic signature of OM. This correlated with improvements in stroke volume and a reduction in heart rate, left ventricle size, and NT-proBNP. An asymptomatic 
increase in plasma troponin of unknown clinical significance was observed. ${ }^{60}$

This trial provided the basis for the Global Approach to Lowering Adverse Cardiac Outcomes Through Improving Contractility in Heart Failure (GALACTIC-HF) trial, which randomized 8256 patients to OM vs placebo from a broad spectrum of $\mathrm{HF}$, in outpatients and stable inpatients, with LVEF $\leq 35 \%$ for $\geq 30$ days, NYHA functional class II-IV, and NT-proBNP $\geq 400 \mathrm{pg} / \mathrm{mL} .{ }^{12}$ Liberal inclusion criteria such as SBP $\geq 85 \mathrm{~mm} \mathrm{Hg}$ and eGFR $\geq 20 \mathrm{~mL} / \mathrm{min} / 1.73 \mathrm{~m}^{2}$ reflected OM's tolerability and potential for broad applicability. The primary outcome of this trial was time to first occurrence of $\mathrm{CV}$ death or an HF event, with the statistical power to detect a reduction in CV death alone. Baseline patient characteristics reflected the high-risk nature of patients, $25 \%$ of whom were enrolled as inpatients. The dose of OM was adjusted according to plasma levels. After a median follow-up of 21.8 months, the OM arm had a lower primary outcome compared with placebo $(37.0 \%$ vs $39.1 \%$; HR, 0.92; 95\% CI, 0.86-0.99; $P=0.03)$. There was no significant interaction among subgroups, except for patients with median EF $>28 \%$, who derived less benefit compared with those with lower EF, a potential signal because of the inherent limitations of a subgroup analysis yet a plausible interaction on a biologic basis. There was no difference in $\mathrm{CV}$ death or HF hospitalizations alone, but HF events trended lower with OM. Reductions in heart rate, and NT-proBNP were observed with $\mathrm{OM}$, and despite a slight increase in median troponin I of $4 \mathrm{ng} / \mathrm{L}$ at week 24 from baseline, there was no difference in adjudicated major cardiac ischemic events, BP, or ventricular arrhythmia due to $\mathrm{OM}$.

\section{Current status and future directions}

Despite OM's modest clinical benefit, GALACTIC-HF proved that unlike conventional inotropes, directly improving contractility through selective cardiac myosin activation with $\mathrm{OM}$ is safe and effective in diverse clinical settings, with no signal for increased CV mortality. Furthermore, OM has no adverse effect on BP, renal function, or electrolytes, and is potentially more beneficial in patients with $\mathrm{EF} \leq 28 \%$. As with other trials, background use of new agents such as SGLT2 inhibitors, was low, but because of the different mechanisms of action, it is plausible that treatment effects would be additive.

$\mathrm{OM}$ is a versatile agent that could be poised for an ancillary role as another line of defense for high-risk patients with history of HF hospitalizations, advanced HF, or those intolerant of neurohormonal antagonists because of hypotension or renal failure.

\section{Net Benefit of New Pharmacological Therapies}

A recent analysis suggested that using mineralocorticoid receptor antagonist, sacubitril/valsartan, and SGLT2 inhibition in addition to conventional treatment with an ACEI/ ARB and $\beta$-blocker results in an additional $40 \%-50 \%$ gain in all of the important CV outcomes, including $\mathrm{HF}$ events, $\mathrm{CV}$ mortality, and all-cause mortality. On the basis of this modelling, a 55-year-old individual can expect to survive an additional 6.3 years because of the newer agents.

\section{Conclusion}

Ongoing scrutiny of existing trial data and additional studies will address remaining knowledge gaps, including the efficacy of these agents in patients with acute and advanced $\mathrm{HF}$, and across the ranges of $\mathrm{EF}$ and glomerular filtration rate. For now, these novel treatments represent an important advance in our quest against HF, but addressing the increasingly complex regimen for HF, cost, and polypharmacy will require creative solutions to ensure optimal use of these novel therapies.

\section{Funding Sources}

Funds for publication were provided by the Cardiovascular Diseases Department, King Faisal Specialist Hospital and Research Centre (Gen. Org.), Jeddah, Saudi Arabia.

\section{Disclosures}

The authors have no conflicts of interest to disclose.

\section{References}

1. Ponikowski P, Anker SD, AlHabib KF, et al. Heart failure: preventing disease and death worldwide. ESC Heart Fail 2014;1:4-25.

2. GBD 2017 Disease and Injury Incidence and Prevalence Collaborators. Global, regional, and national incidence, prevalence, and years lived with disability for 354 diseases and injuries for 195 countries and territories, 1990-2017: a systematic analysis for the Global Burden of Disease Study 2017. Lancet 2018;392:1789-858.

3. GBD 2015 Obesity Collaborators, Afshin A, Forouzanfar MH, et al. Health effects of overweight and obesity in 195 countries over 25 years. N Engl J Med 2017;377:13-27.

4. Alhabeeb W, Elasfar A, AlBackr H, et al. Clinical characteristics, management and outcomes of patients with chronic heart failure: results from the heart function assessment registry trial in Saudi Arabia (HEARTSchronic). Int J Cardiol 2017;235:94-9.

5. Virani SS, Alonso A, Benjamin EJ, et al. Heart Disease and Stroke Statistics-2020 update: a report from the American Heart Association. Circulation 2020;141:e139-596.

6. Owan TE, Hodge DO, Herges RM, et al. Trends in prevalence and outcome of heart failure with preserved ejection fraction. N Engl J Med 2006;355:251-9.

7. Vaduganathan M, Claggett BL, Jhund PS, et al. Estimating lifetime benefits of comprehensive disease-modifying pharmacological therapies in patients with heart failure with reduced ejection fraction: a comparative analysis of three randomised controlled trials. Lancet 2020;396:121-8.

8. McMurray JJ, Packer M, Desai AS, et al. Angiotensin-neprilysin inhibition versus enalapril in heart failure. N Engl J Med 2014;371: 993-1004.

9. Armstrong PW, Pieske B, Anstrom KJ, et al. Vericiguat in patients with heart failure and reduced ejection fraction. N Engl J Med 2020;382: 1883-93.

10. McMurray JJV, Solomon SD, Inzucchi SE, et al. Dapagliflozin in patients with heart failure and reduced ejection fraction. N Engl J Med 2019;381:1995-2008.

11. Packer M, Anker SD, Butler J, et al. Cardiovascular and renal outcomes with empagliflozin in heart failure. N Engl J Med 2020;383:1413-24. 
12. Bhatt DL, Szarek M, Steg PG, et al. Sotagliflozin in patients with diabetes and recent worsening heart failure. N Engl J Med 2021;384: $117-28$.

13. Teerlink JR, Diaz R, Felker GM, et al. Cardiac myosin activation with omecamtiv mecarbil in systolic heart failure. N Engl J Med 2021;384: $105-16$.

14. Stone GW, Lindenfeld J, Abraham WT, et al. Transcatheter mitral-valve repair in patients with heart failure. N Engl J Med 2018;379:2307-18.

15. Abraham WT, Kuck KH, Goldsmith RL, et al. A randomized controlled trial to evaluate the safety and efficacy of cardiac contractility modulation. JACC Heart Fail 2018;6:874-83.

16. FDA. US Food and Drug Administration. FDA approves new treatment for a type of heart failure. Available at: https://www.fda.gov/news-events/pressannouncements/fda-approves-new-treatment-type-heart-failure. Accessed December 7, 2020.

17. FDA. US Food and Drug Administration. FDA approves new indication for valve repair device to treat certain heart failure patients with mitral regurgitation. Available at: https://www.fda.gov/news-events/pressannouncements/fda-approves-new-indication-valve-repair-device-treatcertain-heart-failure-patients-mitral. Accessed December 7, 2020.

18. FDA. US Food and Drug Administration. OPTIMIZER Smart System P180036. Available at: https://www.fda.gov/medical-devices/recentlyapproved-devices/optimizer-smart-system-p180036. Accessed December 7, 2020 .

19. O'Meara E, McDonald M, Chan M, et al. CCS/CHFS heart failure guidelines: clinical trial update on functional mitral regurgitation, SGLT2 inhibitors, ARNI in HFpEF, and tafamidis in amyloidosis. Can J Cardiol 2020;36:159-69.

20. Shubrook JH, Bokaie BB, Adkins SE. Empagliflozin in the treatment of type 2 diabetes: evidence to date. Drug Des Devel Ther 2015;9: 5793-803.

21. Wright EM, Loo DD, Hirayama BA. Biology of human sodium glucose transporters. Physiol Rev 2011;91:733-94.

22. Hsia DS, Grove O, Cefalu WT. An update on sodium-glucose cotransporter-2 inhibitors for the treatment of diabetes mellitus. Curr Opin Endocrinol Diabetes Obes 2017;24:73-9.

23. Silva Da, Nogueira Paula, Da Conceição, et al. Sodium-glucose cotransporter 2 (SGLT-2) inhibitors: a new antidiabetic drug class. Med Chem Comm 2018;9:1273-81.

24. Regier EE, Venkat MV, Close KL. More than 7 years of hindsight: revisiting the FDA's 2008 guidance on cardiovascular outcomes trials for type 2 diabetes medications. Clin Diabetes 2016;34:173-80.

25. Zinman B, Wanner C, Lachin JM, et al. Empagliflozin, cardiovascular outcomes, and mortality in type 2 diabetes. N Engl J Med 2015;373: 2117-28.

26. Neal B, Perkovic V, Mahaffey KW, et al. Canagliflozin and cardiovascular and renal events in type 2 diabetes. N Engl J Med 2017;377: 644-57.

27. Wiviott SD, Raz I, Bonaca MP, et al. Dapagliflozin and cardiovascular outcomes in type 2 diabetes. N Engl J Med 2019;380:347-57.

28. Cannon CP, Pratley R, Dagogo-Jack S, et al. Cardiovascular outcomes with ertugliflozin in type 2 diabetes. N Engl J Med 2020;383:1425-35.

29. ClinicalTrials.gov. Dapagliflozin Evaluation to Improve the LIVEs of Patients With PReserved Ejection Fraction Heart Failure. (DELIVER). Available at: https://clinicaltrials.gov/ct2/show/NCT03619213. Accessed December 7, 2020.
30. Anker SD, Butler J, Filippatos GS, et al. Evaluation of the effects of sodium-glucose co-transporter 2 inhibition with empagliflozin on morbidity and mortality in patients with chronic heart failure and a preserved ejection fraction: rationale for and design of the EMPERORPreserved Trial. Eur J Heart Fail 2019;21:1279-87.

31. Packer M. Critical examination of mechanisms underlying the reduction in heart failure events with SGLT2 inhibitors: identification of a molecular link between their actions to stimulate erythrocytosis and to alleviate cellular stress. Cardiovasc Res 2021;117:74-84.

32. Ali A, Bain S, Hicks D, et al. SGLT2 inhibitors: cardiovascular benefits beyond HbA1c-translating evidence into practice [erratum in: 2019;10: 1623]. Diabetes Ther 2019;10:1595-622.

33. Ferrannini E, Mark M, Mayoux E. CV protection in the EMPA-REG OUTCOME trial: a "thrifty substrate" hypothesis. Diabetes Care 2016;39:1108-14.

34. Packer M, Anker SD, Butler J, Filippatos G, Zannad F. Effects of sodium-glucose cotransporter 2 inhibitors for the treatment of patients with heart failure: proposal of a novel mechanism of action. JAMA Cardiol 2017;2:1025-9.

35. Mentzer RM Jr, Bartels C, Bolli R, et al. Sodium-hydrogen exchange inhibition by cariporide to reduce the risk of ischemic cardiac events in patients undergoing coronary artery bypass grafting: results of the EXPEDITION study. Ann Thorac Surg 2008;85:1261-70.

36. Packer M. SGLT2 inhibitors produce cardiorenal benefits by promoting adaptive cellular reprogramming to induce a state of fasting mimicry: a paradigm shift in understanding their mechanism of action. Diabetes Care 2020;43:508-11.

37. Serenelli M, Böhm M, Inzucchi SE, et al. Effect of dapagliflozin according to baseline systolic blood pressure in the Dapagliflozin and Prevention of Adverse Outcomes in Heart Failure trial (DAPA-HF). Eur Heart J 2020;41:3402-18.

38. Böhm M, Young R, Jhund PS, et al. Systolic blood pressure, cardiovascular outcomes and efficacy and safety of sacubitril/valsartan (LCZ696) in patients with chronic heart failure and reduced ejection fraction: results from PARADIGM-HF. Eur Heart J 2017;38:1132-43.

39. Zannad F, Ferreira JP, Pocock SJ, et al. SGLT2 inhibitors in patients with heart failure with reduced ejection fraction: a meta-analysis of the EMPEROR-Reduced and DAPA-HF trials. Lancet 2020;396:819-29.

40. Hollenberg SM, Warner Stevenson L, Ahmad T, et al. 2019 ACC expert consensus decision pathway on risk assessment, management, and clinical trajectory of patients hospitalized with heart failure: a report of the American College of Cardiology Solution Set Oversight Committee [erratum in: 2020;75:132]. J Am Coll Cardiol 2019;74:1966-2011.

41. Honigberg MC, Vardeny O, Vaduganathan M. Practical considerations for the use of sodium-glucose co-transporter 2 inhibitors in heart failure. Circ Heart Fail 2020;13:e006623.

42. SoRelle R. Nobel prize awarded to scientists for nitric oxide discoveries. Circulation 1998;98:2365-6.

43. Gheorghiade M, Marti CN, Sabbah HN, et al. Soluble guanylate cyclase: a potential therapeutic target for heart failure. Heart Fail Rev 2013;18: 123-34.

44. van Heerebeek L, Hamdani N, Falcão-Pires I, et al. Low myocardial protein kinase $\mathrm{G}$ activity in heart failure with preserved ejection fraction. Circulation 2012;126:830-9.

45. Taylor AL, Ziesche S, Yancy C, et al. Combination of isosorbide dinitrate and hydralazine in blacks with heart failure. N Engl J Med 2004;351: 2049-57. 
46. Levin ER, Gardner DG, Samson WK. Natriuretic peptides. N Engl J Med 1998;339:321-8.

47. Redfield MM, Anstrom KJ, Levine JA, et al. Isosorbide mononitrate in heart failure with preserved ejection fraction. N Engl J Med 2015;373: 2314-24.

48. Redfield MM, Chen HH, Borlaug BA, et al. Effect of phosphodiesterase5 inhibition on exercise capacity and clinical status in heart failure with preserved ejection fraction: a randomized clinical trial. JAMA 2013;309: $1268-77$.

49. Borlaug BA, Anstrom KJ, Lewis GD, et al. Effect of inorganic nitrite vs placebo on exercise capacity among patients with heart failure with preserved ejection fraction: the INDIE-HFpEF randomized clinical trial. JAMA 2018;320:1764-73.

50. Evgenov OV, Pacher P, Schmidt PM, et al. NO-independent stimulators and activators of soluble guanylate cyclase: discovery and therapeutic potential. Nat Rev Drug Discov 2006;5:755-68.

51. Stasch JP, Pacher P, Evgenov OV. Soluble guanylate cyclase as an emerging therapeutic target in cardiopulmonary disease. Circulation 2011;123:2263-73.

52. Pieske B, Maggioni AP, Lam CSP, et al. Vericiguat in patients with worsening chronic heart failure and preserved ejection fraction: results of the SOluble guanylate Cyclase stimulatoR in heArT failurE patientS with PRESERVED EF (SOCRATES-PRESERVED) study. Eur Heart J 2017;38:1119-27.

53. Gheorghiade M, Greene SJ, Butler J, et al. Effect of vericiguat, a soluble guanylate cyclase stimulator, on natriuretic peptide levels in patients with worsening chronic heart failure and reduced ejection fraction: the SOCRATES-REDUCED randomized trial. JAMA 2015;314:2251-62.

54. Butler J, Anstrom KJ, Armstrong PW. Comparing the benefit of novel therapies across clinical trials: insights from the VICTORIA trial. Circulation 2020;142:717-9.

55. CONSENSUS Trial Study Group. Effects of enalapril on mortality in severe congestive heart failure. Results of the Cooperative North Scandinavian Enalapril Survival Study (CONSENSUS). N Engl J Med 1987;316:1429-35.

56. Investigators SOLVD, Yusuf S, Pitt B, et al. Effect of enalapril on survival in patients with reduced left ventricular ejection fractions and congestive heart failure. N Engl J Med 1991;325:293-302.

57. Morgan BP, Muci A, Lu PP, et al. Discovery of omecamtiv mecarbil the first, selective, small molecule activator of cardiac myosin. ACS Med Chem Lett 2010;1:472-7.

58. Teerlink JR, Diaz R, Felker GM, et al. Omecamtiv mecarbil in chronic heart failure with reduced ejection fraction: rationale and design of GALACTIC-HF. JACC Heart Fail 2020;8:329-40.

59. Teerlink JR, Felker GM, McMurray JJV, et al. Acute Treatment With Omecamtiv Mecarbil to Increase Contractility in Acute Heart Failure: the ATOMIC-AHF study. J Am Coll Cardiol 2016;67:1444-55.

60. Teerlink JR, Felker GM, McMurray JJ, et al. Chronic Oral Study of Myosin Activation to Increase Contractility in Heart Failure (COSMIC$\mathrm{HF})$ : a phase 2, pharmacokinetic, randomised, placebo-controlled trial. Lancet 2016;388:2895-903. 